\title{
DESENHO UNIVERSAL PARA APRENDIZAGEM: reflexões sobre o desenvolvimento de aulas de Matemática
}

\author{
Frank Presley de Lima Neves ${ }^{l}$ \\ Jurema Lindote Botelho Peixoto2
}

\begin{abstract}
RESUMO
O contexto educacional inclusivo tensiona um currículo prescritivo, de formato único, pois não tem contemplado diferenças na aprendizagem dos estudantes. Nesse sentido, é importante encontrar alternativas para a experimentação de propostas que se distanciem dessa concepção. Esse estudo teve a finalidade de analisar o desenvolvimento de aulas de matemática na abordagem curricular do Desenho Universal para a Aprendizagem (DUA) e suas implicações para a prática reflexiva do professor. Para tanto, foi desenvolvida uma pesquisa-ação no contexto de uma formação continuada, durante os horários de atividades complementares. A formação enfocou a Educação Inclusiva, a abordagem curricular do DUA, o planejamento e desenvolvimento de aulas de Matemática. Participaram da pesquisa três professores que ensinam Matemática em uma escola pública do sul da Bahia, que possuíam estudantes com deficiência em sua turma. Os dados foram produzidos no processo formativo, a partir da observação participante, registros no diário de campo e relatos escritos dos professores. Os resultados sugerem que o planejamento e o desenvolvimento de aulas baseado no DUA contribuíram para que esses profissionais repensassem sua ação docente de maneira reflexiva e buscassem estratégias de promoção para um ensino de Matemática para todos.
\end{abstract}

Palavras-chave: Desenho Universal para a Aprendizagem. Currículo. Ensino de Matemática.

\section{UNIVERSAL DESIGN FOR LEARNING: reflections about the development of mathematics classes}

\begin{abstract}
The inclusive educational context tenses a prescriptive curriculum in a unique format, since it has not considered differences in students learning. In this sense, it is important to find alternatives for experimenting with proposals that deviate themselves from this conception. This study aimed to analyze the development of mathematics classes in the curricular approach of the Universal Design for Learning (DUA) and its implications for the reflective practice of the teacher. Thus, an action-research was developed in the context of education

Mestre em Educação Matemática. Colégio Estadual Antonio Padilha, Petrolina,
Pernambuco.
Orcid frankneves78@hotmail.com

2 Doutora em Difusão do Conhecimento. Mestre em Matemática. Professora do Programa de Pós-graduação em Educação Matemática da Universidade Estadual de Santa Cruz (PPGEM/UESC), Ilhéus, Bahia. Orcid iD: https://orcid.org/0000-0002-5648-7001. E-mail: jurema@uesc.br
\end{abstract}


during the moments of complementary activities. The training focused on the presuppositions of Inclusive Education, the DUA curriculum approach, and the planning and development of mathematics classes. Three teachers who teach mathematics in a public school in southern Bahia, who had students with disabilities in their class, participated in the research. Data were produced in the formative process, based on participant observation, research field records and written reports from teachers. The results suggest that the planning and development of classes, based on DUA, contributed to these professionals to (re)think about their teaching actions in a reflective way and seeking promotion strategies for a teaching of mathematics for all.

Keywords: Universal Design for Learning. Curriculum. Mathematics Teaching.

\section{DISEÑO UNIVERSAL PARA EL APRENDIZAJE: reflexiones sobre el desarrollo de las clases de matemáticas}

\section{RESUMEN}

El contexto educativo inclusivo presenta un currículo prescriptivo en un formato único porque no ha contemplado diferencias en el aprendizaje de los estudiantes. En este sentido, es importante encontrar alternativas para experimentar con propuestas que se desvíen de esta concepción. Este estudio tuvo como objetivo analizar el desarrollo de las clases de matemáticas en el enfoque curricular del Diseño Universal para el Aprendizaje (DUA) y sus implicaciones para la práctica reflexiva del maestro. Con este fin, se desarrolló una investigación de acción en el contexto de la educación continua durante las horas de actividades complementarias. La capacitación se centró en los supuestos de la Educación Inclusiva, el enfoque curricular de DUA, la planificación y el desarrollo de las clases de matemáticas. Tres maestros que enseñan matemáticas en una escuela pública en el sur de Bahía, que tenían estudiantes con discapacidades en su clase, participaron en la investigación. Los datos se produjeron en el proceso formativo, en base a la observación de los participantes, los registros del diario de campo y los informes escritos de los maestros. Los resultados sugieren que la planificación y el desarrollo de las clases, basados en DUA, contribuyeron a que estos profesionales (re) pensaran en su acción docente de forma reflexiva y buscaran estrategias de promoción para enseñar matemáticas para todos.

Palabras clave: Diseño Universal para el Aprendizaje. Curriculum. Enseñanza de las matemáticas.

\section{INTRODUÇÃO}

Nas últimas décadas, o movimento de inclusão escolar avançou, tanto na implementação de políticas referentes ao acesso dos estudantes, público-alvo da educação especial (PAEE) ${ }^{3}$ na escola comum, como na proposição de mudanças curriculares que considerem suas especificidades (BRASIL, 1988, 1996, 1999, 2015).

Um marco da democratização da educação foi a Constituição brasileira que estabeleceu a "igualdade de condições para o acesso e

3 "Pessoas com deficiência (sensoriais, motoras e intelectuais), transtornos globais do desenvolvimento e com altas habilidades ou superdotação" (BRASIL, 201 1, Art. 1, § $1^{\circ}$ ). 
permanência na escola" (1988, Art. 206, inciso I), bem como a oferta do Atendimento Educacional Especializado (AEE) para estudantes PAEE, preferencialmente na rede regular de ensino (Art. 208).

Nesse contexto, o currículo desempenha um papel crucial na inclusão de estudantes PAEE. O "currículo a ensinar" foi concebido como "uma seleção organizada dos conteúdos a aprender, os quais, por sua vez, regularão a prática didática que se desenvolve durante a escolaridade" (SACRISTÁN, 2013, p. 17).

Mas esse conceito vem sendo ampliado por meio de releituras dos pesquisadores deste campo. A compreensão obtida, até o momento, é que a organização e seleção de conhecimentos nunca foram neutras, pois estiveram e ainda estão relacionadas às questões políticas, ideológicas e culturais, tanto demarcando às práticas escolares como reverberando às mesmas. O currículo envolve "criar condições para que o aluno possa desenvolver conhecimentos e habilidades para inserir-se no mundo e atuar na sua transformação" (ALMEIDA; SILVA, 2011, p. 8).

As mudanças no âmbito do currículo para atender a diversidade de estudantes começaram a ser percebidas desde a Lei de Diretrizes e Bases da Educação (BRASIL, 1996), quando postulava: "os sistemas de ensino devem assegurar currículos, métodos, técnicas, recursos educativos e organização específica para atender às suas necessidades" (Cap V, Art 59). Na mesma década, foi produzido o documento "Parâmetros Curriculares Nacionais: adaptações curriculares e estratégias para a educação de alunos com necessidades especiais", trazendo considerações sobre "o que o aluno deve aprender, como e quando aprender, que formas de organização de ensino são mais eficientes para o processo de aprendizagem, como e quando avaliar o aluno" (BRASIL, 1999, p. 33).

Para Moreira e Baumel (2001, p. 6-10), as primeiras propostas de mudanças curriculares na educação especial refletem a concepção médica de deficiência assumida na época, baseada na busca pela normalização: 
[...] corrigir precedia o educar. Portanto, currículos por desempenho, com modelagem detalhada de respostas e condutas, foram largamente utilizados de forma abstrata e descontextualizados da própria realidade do aluno.

Também advertem para o risco da "simplificação ou descontextualização do conhecimento" (p. 10) nas práticas do currículo na sala de aula e o cuidado com os excessos de individualizações, visto que os estudantes têm condições de participação real, com raras exceções.

Recentemente, a Lei Brasileira da Inclusão (BRASIL, 2015), Cap. IV, Art. 28, cita a necessidade de "III - [...] adaptações razoáveis", para atender às características dos estudantes com deficiência e garantir o seu pleno acesso ao currículo em condições de igualdade, promovendo a conquista e o exercício de sua autonomia". Ainda ressalta a investigação de "novos métodos e técnicas pedagógicas, de materiais didáticos, de equipamentos e de recursos de tecnologia assistiva" (inciso VI), bem como a oferta da formação inicial e continuada de professores para atender os estudantes PAEE e a adoção de práticas inclusivas nestas formações (inciso X).

Até aqui, vimos que os documentos legais asseguram o acesso de todos a uma educação de qualidade. Contudo, a garantia plena desses direitos está relacionada às reformas cruciais no currículo, para além das adaptações curriculares, mas em direção à construção de um cenário novo para a atuação dos professores na sala de aula.

Entretanto, mudanças curriculares não devem ser pensadas apenas por inferências externas ou pela "necessidade de adequar-se". O currículo pode ser compreendido como uma "totalidade em constante 'estado de fluxo"', sendo "significado e ressignificado pelos atores pedagógicos a ele implicados e a instituições nele interessadas, caracteriza-se como uma produção de sujeitos, com suas intenções, sentidos e poderes", um processoproduto, sempre aberto às transformações críticas e participativas provenientes das demandas e grupos emergentes (MACEDO, 2004, p. 258).

\footnotetext{
4 Prova ampliada ou em Braille para o estudante com deficiência visual e cego, prova videografada em Língua Brasileira de Sinais (Libras), entre outras.
} 
Paganelli (2017, p. 1) enfatiza que o termo adaptações curriculares denota "uma mudança pontual, específica para alguns: os 'diferentes'". Assim, segue a lógica da homogeneidade e não da diversidade, dessa forma, o currículo fica "definido pelo déficit, o que ressalta as incapacidades e não as possibilidades dos alunos", muitas vezes, é reduzido por considerar que os estudantes não conseguem acessá-lo. Contudo, a concepção de um currículo flexível vai além, pois:

\begin{abstract}
Flexibilizar significa garantir o direito à diferença no currículo. Implica a busca pela coesão da base curricular comum com a realidade dos estudantes, suas características sociais, culturais e individuais incorporando assim também os diferentes modos de aprender e as múltiplas inteligências presentes em sala de aula. De modo que todos se reconheçam no currículo e sejam protagonistas no próprio processo educacional (PAGANANELLI, 2017, p. 1).
\end{abstract}

Nessa direção, a abordagem do Desenho Universal para a Aprendizagem (DUA), pode oferecer subsídios para promover o debate da inclusão no que se refere a uma concepção de currículos inclusivos em Matemática.

A partir dessas pontuações, destacamos que o objetivo deste estudo foi analisar o desenvolvimento de aulas de Matemática na abordagem curricular do Desenho Universal para a Aprendizagem (DUA) e suas implicações para ação reflexiva do professor.

Neste texto, apresentamos a concepção do DUA, enfatizando os aspectos principais que fundamentam a proposta. Além disso, discutimos a importância do professor reflexivo no contexto educacional inclusivo, situando a formação do professor de matemática. Em seguida, descrevemos os procedimentos metodológicos, a discussão dos resultados e, por fim, as considerações finais.

\title{
O DESENHO UNIVERSAL PARA APRENDIZAGEM: a concepção de um currículo para todos
}

O conceito de Desenho Universal (DU), concebido originalmente na engenharia e arquitetura para "a projeção de edifícios e espaços públicos" 
(ZERBATO; MENDES, 2018, p. 150), tem sido considerado pela legislação brasileira como "concepção de produtos, ambientes, programas e serviços a serem usados por todas as pessoas, sem necessidade de adaptação ou de projeto específico, incluindo os recursos de tecnologia assistiva", conforme a Lei № 13.146/2015 (Cap. 1, Art. 3º, inciso III).

Esse conceito inspirou a abordagem curricular do Desenho Universal para a Aprendizagem (DUA), atribuído a David Rose, Anne Mayer e seus colaboradores do Center for Applied Special Technology (CAST) na década de 1990. O DUA refere-se a princípios e estratégias relacionadas ao desenvolvimento curricular, envolvendo "práticas de ensino a desenvolver junto de alunos com e sem deficiência, centrando-se na dimensão pedagógica" (NUNES; MADUREIRA, 2015, p. 7).

$\mathrm{Na}$ visão dos educadores do CAST, o papel da educação no século XXI ultrapassa a função de domínio de conteúdos e tecnologias para focalizar o domínio do processo de aprendizagem, visando transformar:

Aprendizes iniciantes em aprendizes especializados - indivíduos que querem aprender, que sabem aprender estrategicamente e que, de maneira altamente individual e flexível, estão bem preparados para uma vida inteira de aprendizado. O Desenho Universal para Aprendizagem (DUA) ajuda educadores a atingir esse objetivo, fornecendo uma estrutura para entender como criar currículos que atendam às necessidades de todos os alunos desde o início (CAST, 2011 , p. 4, tradução nossa).

Essa abordagem define o cérebro "como uma rede complexa de redes integradas e sobrepostas. E a aprendizagem é vista como mudanças nas conexões dentro e entre essas redes" (MEYER; ROSE; GORDON, 2000, p. 30, tradução nossa). Desse modo, a aprendizagem está apoiada em "três sistemas básicos: as redes afetivas, as redes de reconhecimento e as redes estratégicas, correspondendo cada uma a um local particular no cérebro e tendo funções específicas" (NUNES; MADUREIRA, 2015, p. 134), conforme a figura 1. 
Figura 1- Localização das redes de aprendizagem no cérebro

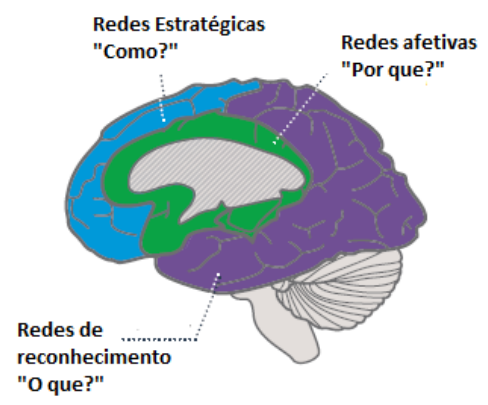

Fonte: CAST $(2018$, p. 1).

As Redes de reconhecimento apontam para "O quê" se pode reconhecer e aprender: "como recolhemos fatos e categorizamos o que vemos, ouvimos e lemos. Identificar letras, palavras ou estilos de autores são tarefas de reconhecimento", refere-se ao princípio da representação (SANTOS, 2015, p. 16). Valoriza-se a flexibilidade na forma de trabalhar os conteúdos, ou seja, na apresentação do mesmo conteúdo de maneiras diversificadas tanto no que tange aos princípios, às abordagens, aos recursos, etc.

As Redes Afetivas relacionam-se com "o porquê" da aprendizagem, enfatizando "como os aprendizes se engajam e permanecem motivados. Como eles são desafiados, como se entusiasmam e se interessam" (SANTOS, 2015, p. 21), refere-se ao princípio do engajamento. Segundo Nunes e Madureira (2015, p. 10), "na realidade, não há um meio de envolvimento e de motivação ideal para todos os alunos em todos os contextos, por isso é essencial implementar múltiplas opções para envolver e motivar os alunos na aprendizagem".

As Redes estratégicas sublinham "o como" da aprendizagem, é o momento de expressar o que foi compreendido, enquanto planeja e executa ações, enquanto organiza e expressa ideias, seja "escrevendo um ensaio ou resolvendo um problema de Matemática são tarefas estratégicas" (SANTOS, 2015, p. 16). Essas funções referem-se ao princípio da Ação e Expressão. A orientação para o professor é: diferenciar as formas pelas quais os alunos expressão o que sabem. 
Desta forma, o DUA defende um currículo flexível, aberto, que vise a ampliação de possibilidades no ensino e a variedade de estudantes, que seja contrário a um currículo de "tamanho único" e prescritivo, e que considere estilos de aprendizagem diferentes: "alguns [estudantes] são aprendizes visuais, outros são aprendizes auditivos e alguns são aprendizes práticos. E cada estudante tem suas preferências e maneiras de expressar seu conhecimento" (ZERBATO; MENDES, 2018, p. 149).

\section{DA FORMAÇÃO REFLEXIVA NO CONTEXTO EDUCACIONAL INCLUSIVO}

Pensar a formação docente, seja inicial ou continuada, pressupõe colocar a escola como espaço-tempo de construção de experiências e, ao mesmo tempo, de problematização de sua dinâmica, a qual é tecida diariamente pela ação político-pedagógica do professor e demais profissionais que constituem esse contexto. Nesse sentido, a formação se caracteriza como um continuum, algo que se prolonga em toda a vida profissional e, portanto, não se encerra com a conclusão de uma licenciatura.

Partindo do pressuposto que o alicerce da educação é a "formação" e considerando a falta de análises explícitas sobre a relação desse fenômeno com o currículo e o saber, Macedo (2011, p. 15-16) defende a "formação como uma centralidade reflexiva e práxica", desenvolvida por intermédio de "ações curriculares e na emergência de aprendizagens significativas, a uma realização humana complexa". Pois, segundo o autor, a ruptura formação-currículo não favorece o ato educativo, seja na fragmentação e simplificações dos conhecimentos eleitos como formativos, sejam nas reificações ou naturalizações da realidade humana, seja na despolitização que omite a reflexão e explicitação sobre relações embutidas nas propostas curriculares.

Para consolidar essa fratura, a formação deve ser compreendida como um "analisador e um revelador filosófico e político-pedagógico" para tensionar "ações educacionais que se pretendem formativas" em um currículo "exterodeterminado", bem como mover o debate nos cenários 
educacionais, buscando a valorização do professor que produz conhecimento, sendo cada vez mais reflexivo, crítico, autônomo, implicado em suas atividades na "emergência do sujeito em formação" (MACEDO, 2011 , p. 15, grifo do autor).

Entretanto, uma formação assentada, geralmente, no paradigma da racionalidade técnica, cujo foco está na dimensão aplicacionista do conhecimento (MOREIRA; DAVID, 2005), não tem se mostrado suficiente para ajudar o professor a compreender a realidade e criar alternativas para o seu enfrentamento, pois a prática não pode ser reduzida a dimensão técnica e o conhecimento do professor "não pode ser visto como um conjunto de técnicas ou como um kit de ferramentas para a produção da aprendizagem" (DINIZ-PEREIRA, 2014, p. 37).

Dessa constatação, concebe-se o conceito de professor reflexivo (SCHÖN, 1992, 2000), fundamentado na epistemologia da prática, em que há a valorização da prática profissional como momento de construção de conhecimento, envolvendo a reflexão, a análise, a problematização e mobilização de conhecimentos tácitos.

É no continnum do fazer docente que a reflexão vai acontecendo e mobilizando saberes, sentidos e práticas. Segundo Schön (1992), a prática da reflexão envolve três processos importantes: reflexão na ação, reflexão sobre a ação e a reflexão sobre a reflexão na ação.

A reflexão na ação ocorre durante o decurso, sem interrompê-la, é um processo mental quase automático, reflete-se sobre situações novas que extrapolam suas experiencias prévias, permitindo dar um novo delineamento ao que se faz, possibilitando interferir na situação em curso.

A reflexão sobre a ação corresponde à reconstrução mental da ação, envolve análise retrospectiva, agregando a vivência ao repertório de experiências práticas, é intencional, exigindo da pessoa disposição para tal que pode influenciar ações futuras.

E a reflexão sobre a reflexão na ação é um processo a posteriori, baseado em um conjunto de reflexões que leva o profissional a progredir no seu desenvolvimento e a construir sua forma pessoal de conhecer, 
consolidando o entendimento da situação vivenciada, possibilitando a adoção de novas estratégias.

Para além da epistemologia da prática, nasce a epistemologia crítica, em que a educação é concebida como uma atividade social e política, "afetando as escolhas de vida daqueles envolvidos no processo" (DINIZPEREIRA, 2014, p. 39).

Nesse contexto, o conceito de professor reflexivo foi ampliado por Zeichner (1992 apud PIMENTA, 2005, p. 26), visando ressaltar a importância da reflexão coletiva. Assim, baseado em pesquisas com professores nas escolas $O$ autor formulou três perspectivas que devem funcionar simultaneamente:

a) a prática reflexiva deve centrar-se tanto no exercício profissional dos professores por eles mesmos, quanto nas condições sociais em que esta ocorre; b) o reconhecimento pelos professores de que seus atos são fundamentalmente políticos e que, portanto, podem se direcionar a objetivos democráticos emancipatórios; c) a prática reflexiva, enquanto prática social, só pode se realizar em coletivos, o que leva a necessidade de transformar as escolas em comunidades de aprendizagem nas quais os professores se apoiem e se estimulem (ZEICHNER, 1992 apud PIMENTA, 2005, p. 26).

A reflexão da prática do professor poderá ser provocada inicialmente no estabelecimento de espaços destinados para tal função. As comunidades de aprendizagem constituem um "ambiente intelectual, social, cultural e psicológico que facilita e sustenta a aprendizagem, enquanto promove a interação, a colaboração e a construção de um sentimento de pertença entre os membros" (AFONSO, 2001, p. 429).

A promoção de ambientes desse tipo, articulando profissionais da escola e universidades, pode favorecer a reflexão, a consciência de si, do espaço e do outro, em prol da transformação social. A perspectiva de uma Comunidade de Aprendizagem rompe com a tradição sobre a produção do conhecimento localizada apenas nas universidades e centros de pesquisa para valorizar os saberes dos professores, dos próprios estudantes e dos espaços escolares diante dos desafios resultantes das mudanças na sociedade. 
As rápidas mudanças no mundo do trabalho, o avanço da tecnologia, configurando a sociedade virtual, os meios de comunicação e o processo de implementação da inclusão socioeducacional, resultado de lutas sóciohistóricas, "incidem fortemente na escola, aumentando os desafios para torná-la uma conquista democrática efetiva" (PIMENTA; LIMA, 2004, p. 12), com equidade nas oportunidades de aprender e ensinar.

No contexto da formação de professores para uma Educação Matemática mais inclusiva, Manrique e Maranhão (2016, p. 24) reconhecem que "a tarefa de formar professores tem se tornado cada vez mais complexa", devido a vários fatores, como: a desvalorização da profissão docente, a diversidade de estudantes na aula, proveniente da ampliação do acesso, o reconhecimento das múltiplas competências para assumir essa função numa estrutura de escola que não foi concebida para tal missão e a disseminação e uso das tecnologias que trazem novas formas de ensinar e aprender.

Essa nova configuração de sociedade exige nova configuração de escola e nova postura por parte do professor. Além de ser comprometido com sua função, ele deve ser participativo e aprender a atuar em colaboração.

A participação de professores da Educação Básica em uma Comunidade de Aprendizagem, constituída por diferentes sujeitos em variadas fases de sua trajetória profissional, tem implicações e consequências muito importantes para a investigação sobre o ensino e aprendizagem em Matemática (MANRIQUE; MARANHÃO, 2016, p. 35).

A atuação exigida deve ultrapassar "a racionalidade técnica", que transforma os professores em meros executores de propostas curriculares e educacionais, para alcançar atuação de professores de forma crítica, reflexiva, implicada, autônoma na produção/gestão de currículo ou projetos educacionais, utilizando, para tanto, sua capacidade de decisão.

Quando os professores compreendem e investigam a sua prática, eles podem agir de forma "consciente", não se baseando apenas no improviso de ações mecânicas. Isso porque "as transformações das práticas docentes 
só se efetivarão se o professor ampliar sua consciência sobre a própria prática, a de sala de aula e a da escola como um todo, o que pressupõe os conhecimentos teóricos e críticos sobre a realidade" (PIMENTA; LIMA, 2004, p. 13).

Nesse sentido, o conhecimento profissional torna-se relevante para gerir uma aula matemática para todos no contexto educacional inclusivo:

\begin{abstract}
O professor precisa estar bem preparado para lidar com um leque variado e altamente diferenciado de alunos. Para além de um conhecimento sólido em matemática, necessita conhecer bem os seus alunos, na sua diversidade, bem como metodologias diversificadas que the permitam fazer opções adaptadas às diferentes situações e promover a participação de todos os alunos. Para que esse conhecimento vá se consolidando, é importante que o professor investigue e reflita sobre a sua própria prática (MARTINHO, 2016, p. 9).
\end{abstract}

Dentre o conjunto de desafios a serem problematizados e enfrentados pelos professores na prática diária, está a inclusão de educandos PAEE. Na presença desses estudantes, professores de matemática buscam acionar saberes, conhecimentos e competências construídas ao longo da formação inicial, a qual não vem dando conta de responder a essa demanda (MUNIZ, 2018; MUNIZ; PEIXOTO; MADRUGA, 2018) e a muitas outras que surgem, face à complexidade do real, ou seja, da escola e da sala de aula.

Podemos então afirmar que é preciso fornecer subsídios teóricos e metodológicos para provocar, colaborativamente, os futuros ou já professores para atuarem em um novo contexto, em que possam ser mediadores do conhecimento, levando em conta a diversidade de estudantes na sua sala de aula. Mas como seria uma formação continuada para uma educação para todos? Kranz (2011) sinaliza que:

A princípio, seria uma formação na perspectiva de fazer com os professores, e não para eles, entendendo-os como sujeitos aprendentes, com saberes e não saberes. Também uma formação que possa (re)pensar as concepções que norteiam a aprendizagem matemática dos alunos com deficiência, no que diz respeito à deficiência, à Matemática, à aprendizagem e ao desenvolvimento infantil (KRANZ, 2011, p. 133, grifo nosso). 
O professor precisa ter consciência de que as transformações sociais têm requerido uma educação plena de significados, tendo por finalidade levar o sujeito e, ele próprio, a aprender em um processo de ação-reflexãoação. Para que isso ocorra, os espaços formativos precisam criar conversações reflexivas, onde haja coesão entre a formação e currículo, além de permitir, ao trabalho docente, atividades de pesquisa e aperfeiçoamento humano, profissional e cidadão.

\section{PROCEDIMENTOS METODOLÓGICOS}

O processo formativo foi desenvolvido utilizando $O$ modelo metodológico da espiral Reflexão-Planejamento-Ação-Reflexão (REPARE), elaborado por Magina (2008) para desenvolver ações formativas com viés colaborativo. Nessa espiral, o movimento começa pela reflexão sobre:

O ensino e a aprendizagem, que significa o professor refletir a respeito das suas concepções matemáticas e também de seus estudantes, concernentes, nesse caso, ao objeto matemático de ensino, e refletir tanto individual como coletivamente sobre o mesmo. Após essa reflexão, à luz de uma teoria, o professor passa a planejar, coletivamente, novas atividades matemáticas para então agir em sala de aula. Ao agir esse professor estará expandindo esse Campo Conceitual junto a seus estudantes para, posteriormente, refletir individual e/ou coletivamente sobre a ação realizada (MERLINI; SANTOS; MAGINA, 2017, p. 128).

O campo de pesquisa foi uma escola pública da rede estadual de ensino de uma cidade do sul da Bahia que atendia estudante com deficiência (critério de seleção). A escola obteve, em 2016, uma Sala de Recursos Multifuncionais, onde é realizado o Atendimento Educacional Especializado em dois turnos, atendendo 18 estudantes com Deficiência Intelectual, matriculados no ensino fundamental (10) e médio (8), sendo seis estudantes da demanda espontânea.

Participaram da investigação três professores que lecionam matemática no Ensino Fundamental e Médio5. No momento da pesquisa, todos tinham estudantes com deficiência intelectual na sala de aula, um em

\footnotetext{
5 Participação condicionada pela aprovação do projeto no Comitê de Ética em Pesquisa
} sob o CAAE: 88740318.3.0000.5526.

Revista Exitus, Santarém/PA, Vol. 10, p. 1-30, e020009, 2020. 
cada turma. Os professores foram identificados por nomes fictícios de Hipotenusa, Cateto e Triângulo. O seu perfil é detalhado no Quadro 1.

QUADRO 1 - Perfil dos professores

\begin{tabular}{|c|c|c|c|}
\hline Identificação & Formação & Idade & Tempo de serviço \\
\hline Hipotenusa & $\begin{array}{c}\text { Bacharel em administração e } \\
\text { Licenciada em Matemática } \\
\text { Especialização em Educação Infantil }\end{array}$ & 52 & 20 anos \\
\hline Cateto & $\begin{array}{c}\text { Licenciado em Física } \\
\text { Mestrando em Educação em Ciências }\end{array}$ & 28 & 4 anos \\
\hline Triângulo & $\begin{array}{c}\text { Licenciado em Matemática } \\
\text { Especialização em ensino de } \\
\text { matemática }\end{array}$ & 49 & 17 anos \\
\hline
\end{tabular}

Fonte: Dados da pesquisa.

O processo formativo foi planejado e realizado nos horários semanais das atividades complementares com a duração de cinco encontros de três horas/aula cada, sendo que, em alguns momentos, houve compartilhamento de informações pelas mídias sociais.

Nos primeiros encontros, foram abordados: os pressupostos da História da educação especial, da concepção de deficiência, dispositivos legais, especificidades educacionais dos estudantes com deficiência (deficiência intelectual), a abordagem do Desenho Universal para a Aprendizagem (DUA). Após cada encontro, cada professor foi convidado a elaborar um relato escrito para ser entregue no próximo encontro.

Os quatro últimos encontros foram destinados para o planejamento de uma aula de matemática segundo a abordagem do DUA, bem como para a reflexão sobre o seu desenvolvimento na turma. O pesquisador colaborou com o processo de planejamento da aula, mas apenas observou, sem interferir, o desenvolvimento da mesma. Cada professor elaborou seu plano de aula (2horas/aula) segundo a abordagem do DUA, envolvendo os princípios de engajamento, representação e ação/expressão. 


\section{RESULTADOS E DISCUSSÃO}

Será desenvolvida uma análise interpretiva sobre o processo formativo em dois momentos, a saber: Reflexão inicial e Planejamento - Ação Reflexão.

\subsection{Da Reflexão inicial}

A reflexão inicial considerou a proposição: os professores em serviço articulam saberes diversos em suas práticas que podem ser tomados como disparadores da reflexão de conceitos teóricos e práticos sobre o contexto inclusivo. Assim, o impulso dado para mover a espiral REPARE foi tematizar o contexto educacional inclusivo desde o processo histórico da educação, conceito de deficiência, passando pelas especificidades dos estudantes atendidos pelos professores até o conceito da abordagem currricular do DUA.

$\mathrm{Na}$ discussão sobre o conceito de deficiência, os professores apresentaram compreensões que se aproximam do modelo médico da deficiência, ou seja, focado no déficit em oposição às potencialidades, no que "falta" ao estudante: "Como a falta de algo assim o aluno apresenta algum problema físico ou algum problema intelectual tipo um déficit de aprendizagem considero a isso tipo alguma coisa, que falte no aluno" (Prof. Cateto, 2018).

Ao longo das conversas, as falas revelaram indícios de uma concepção que reconhece a potencialidade do estudante, baseado no modelo social, em que a deficiência é potencializada pelas barreiras encontradas na sociedade: "Algo que não foi desenvolvido em algum momento na vida daquela criança [...] não há progresso de aprendizagem" (Profa. Hipotenusa, 2018). O professor triângulo compreende que: "O menino tem deficiência física, mas ele desenvolve o psíquico dele tranquilamente".

Na perspectiva de formação colaborativa, é preciso entender que os professores são "sujeitos aprendentes, com saberes e não saberes" (KRANZ, 2011, p. 133), assim, trazer para o debate o conceito da deficiência, especificamente, de deficiência intelectual foi importante para que os 
professores ampliassem sua visão para vislumbrar formas de organizar o planejamento na sua turma.

A deficiência intelectual (DI), denominada antes de "deficiência mental"6, pode ser definida por:

\begin{abstract}
Um funcionamento intelectual geral significativamente abaixo da média, oriundo de um período de desenvolvimento, concomitante com limitações associadas a duas ou mais áreas da conduta adaptativa ou da capacidade do indivíduo em responder adequadamente às demandas da sociedade, nos seguintes aspectos: comunicação; cuidados pessoais; habilidades sociais; desempenho na família e comunidade; independência na locomoção; saúde e segurança; desempenho escolar; lazer e trabalho (BRASIL, 1999, p. 26).
\end{abstract}

Para que haja um desenvolvimento dos estudantes com DI, Silva (2014) enfatiza que a comunidade escolar precisa reconhecer as várias formas de ser e aprender desse estudante. Para tanto, recomenda que o professor busque: favorecer o entrosamento do estudante com DI através de atividades em grupo; identificar suas competências e habilidades, visando promover sua participação; desenvolver uma orientação gradual das tarefas, utilizando estratégias diversificadas, pois seu aprendizado se desenvolve em um ritmo mais lento; perguntar sempre sobre seu entendimento do assunto.

Sobre o tema da educação inclusiva, os professores oscilavam desde à descrença ao reconhecimento de sua necessidade, sinalizando dificuldades na implementação: "Eu acho que é uma utopia [...] o professor na sala de aula com 35 alunos... impossivel" (Profa. Hipotenusa, 2018). A visão baseada na dialética normal/anormal foi identificada nas falas dos professores Triângulo e Cateto: "tentar incluir ao máximo aquele aluno no nosso universo, no universo que a gente julga ser normal [...] incluir ele nesse universo é que muitas vezes é o grande problema nosso" (Prof. Triângulo, 2018). Entretanto, o professor Cateto acredita ser possível: "Eu acredito que seja a melhor maneira de se introduzir um aluno em um contexto em sala de

\footnotetext{
6 Em 2004, a Organização das Nações Unidas (ONU) recomendou substituir esse termo para evitar confusões com a "doença mental" ou psiquiátrica (SILVA, 2014).
} 
aula justamente para fazer essa inclusão com os outros que, entre aspas, assim consideramos, normais".

Os desafios colocados pelos professores Triângulo e Hipotenusa, coadunam com a concepção de Manrique e Maranhão (2016) sobre um aspecto que dificulta o processo de inclusão: a diversidade de estudantes na aula exige múltiplas competências do professor numa estrutura de escola que não foi concebida para tal missão.

O DUA fornece uma estrutura para desenvolver currículos (metas, métodos, materiais e avaliação) que podem subsidiar o planejamento da aula e pensar a prática de forma não convencional. O objetivo é "reduzir barreiras, bem como aperfeiçoar os níveis de desafio e apoio, para atender as necessidades de todos os estudantes desde o inicio" da escolaridade (CAST, 2011 , p. 4).

Nesse tema, os relatos revelaram uma compreensão dos aspectos principais desse conceito e sua viabilidade no ensino de Matemática:

Neste encontro tive um contato mais amplo e compreensível do que é o Desenho Universal para Aprendizagem (DUA). Este consiste em elaborar estratégias para a acessibilidade. Não uma única estratégia, mas um conjunto de estratégias para toda a turma (Prof. Cateto - Relato escrito, 2018).

Essa acessibilidade, a qual se refere o professor Cateto, não se reduz às questões de remoção de barreiras arquitetônicas, mas, principalmente, as de natureza pedagógica. O DUA tem por finalidade "eliminar barreiras desnecessárias sem eliminar os desafios necessários, concentrando-se no acesso a todos os aspectos da aprendizagem" (CAST, 201 1, p. 3).

A descrição minuciosa do professor Triângulo revela que, por trás da teoria, há inúmeros aspectos que podem auxiliar a prática docente, como por exemplo, a própria questão da motivação e sua importância no processo de ensino e aprendizagem; a significação do conteúdo, tanto para o professor quanto para o aluno; a necessidade de envolver o aluno (incluílo), a necessidade do trabalho pedagógico alcançar a todos; a aula não ser configurada em formato único, mas possibilitar caminhos variados para a aprendizagem e sua avaliação: 
São 3 pilares de sustentação do DUA: Motivação, Representação e Avaliação. Motivação: o aluno tem que ser provocado por meios que se sinta motivado e envolvido para realização dos trabalhos propostos em sala de aula de forma significativa. O aluno tem que fazer parte do ambiente que está inserido. Representação: 0 trabalho desenvolvido em sala deve ser apresentado de forma que contemple todos os alunos da turma. A aula não deve ser feita ou produzida em um único formato, é preciso diversificar e usar diferentes métodos para que os alunos consigam assimilar da melhor maneira possível o planejamento traçado pelo professor. Avaliação: o professor deverá apresentar diversas formas de avaliação, seja ela escrita, oral ou em forma de desenho, entre outras. Temos que atender a todos de maneira que se sintam livres para expressar a sua forma de compreender os conteúdos que foram trabalhados.

A professora Hipotenusa destacou na sua reflexão as redes de aprendizagem e suas relações com a forma de aprender de cada um:

Pude compreender que a DUA - Desenho Universal na Aprendizagem consiste na elaboração de estratégias para o serviço educacional. Foi também inspirada na neurociência cognitiva que procura entender como o cérebro funciona e os pontos importantes para isto foi descoberto as REDES. 1. Redes afetivas - aprendizagens com significados; 2. Redes de reconhecimento - reúne o que vê, ouve e lê, ou seja, tarefas de reconhecimento; 3. Redes estratégicas - o que é o planejamento e a execução das tarefas.

Através do diálogo dos referenciais teóricos no processo formativo, os conceitos foram sendo compreendidos e refletidos, em maior ou menor grau de elaboração como foi verificado nos relatos dos professores. Desse modo, os professores obteram subsídios para planejarem suas aulas, visando atender sua turma e incluir os estudantes com DI.

\subsection{Planejamento-Ação-Reflexão}

Os professores pensaram o planejamento da aula, de forma individual, mas, ao mesmo tempo, pensaram coletivamente. Um contribuía com a ideia do outro, enriquecendo assim, as discussões e possibilidades de desenvolvimento da ação pedagógica.

Nesse momento, o individualismo deu lugar a uma reflexão que, segundo Zeichner (1992 apud PIMENTA, 2005, p. 26), "só pode se realizar em coletivos, o que leva a necessidade de transformar as escolas em 
comunidades de aprendizagem nas quais os professores se apoiem e se estimulem".

A professora Hipotenusa desenvolveu seu plano de aula para duas horas/aula, em uma turma do $6^{\circ}$ ano do Ensino Fundamental, composta por 25 estudantes, dentre esses, duas estudantes com DI. O plano de aula envolveu a unidade temática Geometria: sólidos geométricos. O Quadro 2, explicita o plano da professora:

Quadro 2 - Plano de aula da professora Hipotenusa

\begin{tabular}{|c|c|}
\hline & Mate \\
\hline $\begin{array}{l}\text { Sólidos geométricos: Poliedros e corpos } \\
\text { redondos. } \\
\text { - Classificar e diferenciar poliedros e } \\
\text { corpos redondos. } \\
\text { - Identificar nos poliedros vértices, } \\
\text { arestas e faces e suas relações. }\end{array}$ & $\begin{array}{l}\text { Envolvimento } \\
\text { Atividade individual: Pesquisa bibliográfica } \\
\text { em casa (internet, livros, etc.) e busca de } \\
\text { embalagens ou objetos com forma de } \\
\text { Poliedros e corpos redondos. } \\
\text { Atividade em grupo. } \\
\text { Representação } \\
\text { Material manipulável, embalagens. } \\
\text { Ação / Expressão } \\
\text { Exposição oral e avaliação escrita. }\end{array}$ \\
\hline \multicolumn{2}{|c|}{ Metodologia } \\
\hline \multicolumn{2}{|c|}{$\begin{array}{l}\text { Cada grupo discutirá entre si os conceitos pesquisados para fazer uma breve } \\
\text { apresentação. Após cada apresentação, o próximo grupo pode apresentar a sua } \\
\text { pesquisa, comentado a aprentação anterior, acrescentando, concordando ou } \\
\text { discordando. Após esse momento, os estudantes manusearão as embalagens e } \\
\text { objetos, discutindo entre si, para classificar, bem como identificar os elementos } \\
\text { (vértices, faces e arestas). No final, registrarão os resultados, de forma individual na } \\
\text { folha de papel A4. }\end{array}$} \\
\hline
\end{tabular}

Fonte: Arquivo da pesquisa.

Na narrativa da professora Hipotenusa sobre o desenvolvimento da sua aula, surgiram estratégias novas no enfrentamento dos desafios postos na e pela ação:

Quando comecei a aula ... ai fiquei assim...eu vou começar...toda hora eu falava vou começa ...aí eu pedi a eles pra fazer a leitura...teve um momento que eu fui fraca...aí eu estava assim...eu estou fugindo...vou voltar para meu objetivo... senão vou sair dele...eu tive esses conflitos comigo e segui minha aula, respirei e falei... o que der deu...eu vou aprender com meu erro ... e foi aquele turbilhão de coisas que naquele momento que eu estava fazendo o planejamento... Então eu me centralizei ali... então eu desenvolvi a aula. 
Nesse momento, parece que houve uma pausa para a reflexão da prática (na ação), na medida em que pensou seu fazer, como e por que fazia. Nesse excerto, identifica-se também a reflexão sobre a reflexão na ação, pois à medida que professores descrevem o processo reflexivo de sua ação (re)pensam a prática e, por conseguinte, podem alterá-la (SCHÖN, 1992).

A figura 2 mostra duas cenas da aula da professora Hipotenusa, uma do grupo de estudantes, em que a estudante com DI participava e a outra mostrando a professora interagindo com outro grupo durante a atividade com embalagens.

FIGURA 2 - Cenas da aula da professora Hipotenusa

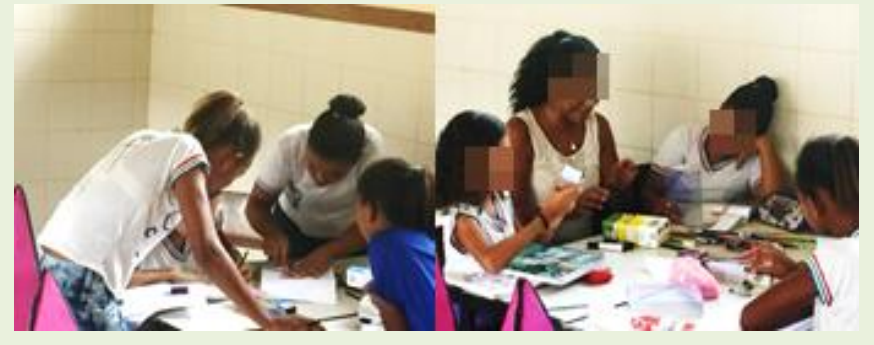

Fonte: Arquivo da pesquisa.

Sobre a avaliação de sua aula, Hipotenusa destacou que "Cada um do seu jeito e ele não consegue fazer, daquele jeito que é esperado, mais sim do jeitinho dele, nós vamos observando e anotando e comunicando uma professora com a outra essas limitações apresentadas".

Essa afirmação mostra que a professora reconhece as singularidades dos estudantes, além de revelar a importância das trocas de experiências, estímulo e apoio entre os pares "em variadas fases de trajetória profissional" (MANRIQUE; MARANHÃO, 2016, p. 35), formando assim, um ambiente propício para "favorecer a reflexão, a consciência de si, do espaço e do outro, em prol da transformação social" (AFONSO, 2001, p. 429).

No seu processo reflexivo, a professora Hipotenusa admitiu que 0 currículo precisa atender a diversidade de estudantes e não pode planejar sua aula sem pensar nesse aspecto: "Eu cheguei a compreender [....] antes eu não fazia assim [...] Eu ficava fazendo aquele processo como se todo 
mundo fosse igual, eu não fazia a aula acontecer para todos". A professora teve consciência de que sua prática não tornava sua aula acessível com equidade nas oportunidades de ensinar e aprender. Portanto, mudanças precisam ser vislumbradas para que a escola se transforme em um espaço democrático e efetivo (PIMENTA; LIMA, 2004).

O professor Triângulo desenvolveu a sua aula em uma turma do $9^{\circ}$ ano composta por 32 estudantes (incluindo uma estudante DI), abordou a unidade temática álgebra e funções, conforme explicita seu planejamento no Quadro 3.

Quadro 3 - Plano de aula do professor Triângulo

\begin{tabular}{|c|c|}
\hline Conteúdos/objetivos & Materiais / Recursos \\
\hline $\begin{array}{l}\text { Função polinomial do } 1^{\circ} \text { grau. } \\
\text { - Compreender função como uma } \\
\text { relação entre grandezas, identificando } \\
\text { variável dependente e independente e } \\
\text { representação algébrica. } \\
\text { - Perceber a relação existente entre } \\
\text { algumas situações vivenciadas no dia a } \\
\text { dia e o conteúdo. }\end{array}$ & $\begin{array}{l}\text { Envolvimento } \\
\text { Pesquisa bibliográfica sobre o conceito de } \\
\text { função, confecção de material para } \\
\text { exposição na turma. } \\
\text { Representação } \\
\text { Exposição áudio visual no formato de slides } \\
\text { (Power Point) com figuras representando } \\
\text { situações cotidianas. Apresentação de um } \\
\text { vídeo youtube sobre as variações no preço } \\
\text { da gasolina. Confecção de cartazes pelos } \\
\text { estudantes. } \\
\text { Ação / Expressão } \\
\text { Exposição oral e escrita. }\end{array}$ \\
\hline \multicolumn{2}{|c|}{ Metodologia } \\
\hline \multicolumn{2}{|c|}{$\begin{array}{l}\text { Para introdução da aula de funções, serão discutidas diversas situações que poderão } \\
\text { caracterizar uma relação de função, por exemplo, a relação de bens de consumo, } \\
\text { através de uma apresentação em slides (power point). Em seguida, solicitar uma } \\
\text { pesquisa bibliográfica sobre diversas situações cotidianas que caracterizam uma } \\
\text { relação de função. Na próxima aula, será feita uma apresentação de um vídeo sobre } \\
\text { as osciliações no preço da gasolina, em seguida dialogar com os estudantes se eles } \\
\text { conseguem identificar relações funcionais. Em grupo, todos os estudantes farão } \\
\text { apresentação do conceito para a turma (usando cartazes ou o que desejarem). }\end{array}$} \\
\hline
\end{tabular}

Fonte: Arquivo da pesquisa.

O professor Triângulo avaliou a aula como uma "tentativa" de motivação:

A gente tentou motivar, trouxe um assunto que diz respeito a todos de uma forma geral, quando a gente estava trabalhando a aula de funções [...] no meu caso acho que foi assim... faltou um pouco mais de tempo pra gente trabalhar isso certo, bem as aulas poderiam ter tido um formato mais completo. 
A reflexão sobre a reflexão na ação foi realizada pela descrição da reflexão na ação, quando o professor narra o processo reflexivo de sua ação, (re)pensa a sua prática, consolidando o entendimento da situação vivenciada, possibilitando a adoção de novas estratégias (SCHÖN, 1992).

Em relação à inclusão da estudante com DI no grupo, o professor expressou perplexidade e, certo contentamento, em perceber a participação da estudante com Dl, analisando o seu envolvimento e desempenho durante a atividade:

Vocês viram a aluna DI do nono ano, vocês observaram uma coisa importante que traz para a gente. Ela lê bem [...] participou ativamente, dentro das características dela, e estava lá, enquanto outros estavam olhando no início, ela foi com o grupo lá na frente, e eu queria que a outra DI estivesse lá também (Prof. Triângulo, 2018).

Para além de um conhecimento sólido em matemática, é preciso conhecer os estudantes, "bem como metodologias diversificadas que the permitam fazer opções adaptadas às diferentes situações e promover a participação de todos" (MARTINHO, 2016, p. 9). A figura 3 apresenta cenas da aula do professor Triângulo.

FIGURA 3 - Cenas da aula do professor Triângulo: apresentação em grupo

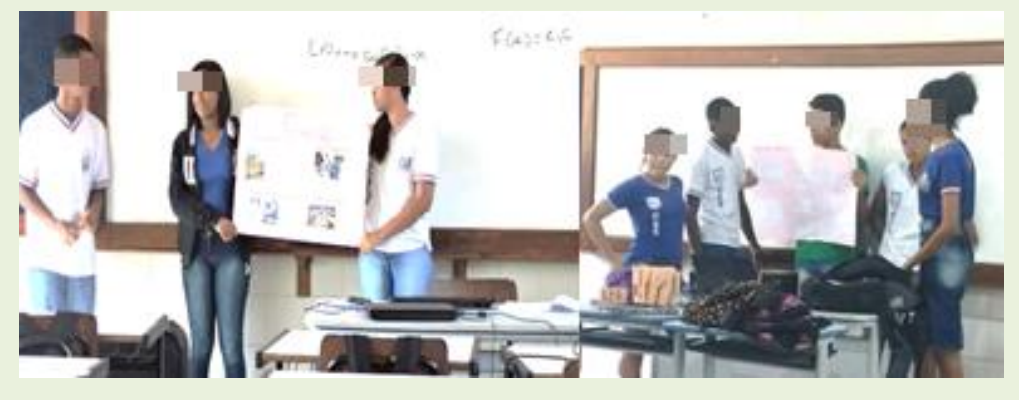

Fonte: Arquivo da pesquisa.

O professor Triângulo começa a perceber as possiblidades que se apresentam a partir do processo formativo:

Por não ter tido essa formação e acabar não buscando, a gente coloca essas situações como entraves, mas hoje eu já enxergo, já vejo de uma forma um pouco diferente, que eu posso fazer algo diferente, mesmo com todos esses trabalhos, a gente pode fazer algo diferente. 
A reflexão de Triângulo sobre o processo vivenciado mostra os elos em construção: formação e ações curriculares, saberes e fazeres "na emergência de aprendizagens significativas" (MACEDO, 2011, p.15).

O professor Cateto também abordou na sua aula a unidade álgebra e funções, numa turma do $1^{\circ}$ ano do Ensino Médio, composta por 40 estudantes. O Quadro 3 mostra o plano de aula do professor Triângulo.

Quadro 3 - Plano de aula do professor Triângulo

\begin{tabular}{|c|c|}
\hline Conteúdos/objetivos & Materiais / Recursos \\
\hline $\begin{array}{l}\text { - Função Exponencial e suas } \\
\text { representações. } \\
\text { - Reconhecer a relação de grandezas e } \\
\text { representação gráfica de uma função } \\
\text { exponencial, associando-a a seu padrão } \\
\text { de crescimento ou decrescimento. }\end{array}$ & $\begin{array}{l}\text { Envolvimento } \\
\text { Atividade individual: pesquisa bibliográfica } \\
\text { Atividade em grupo, debate. } \\
\text { Representação } \\
\text { Mapa conceitual, gráficos de funções em } \\
\text { folha impressa. } \\
\text { Ação / Expressão } \\
\text { Exposição escrita e oral. }\end{array}$ \\
\hline \multicolumn{2}{|r|}{ Metodologia } \\
\hline \multicolumn{2}{|c|}{$\begin{array}{l}\text { As aulas serão desenvolvidas de acordo com as etapas: 1) Pedir aos alunos para } \\
\text { fazerem uma pesquisa (em casa) de reportagens que envolvam situações de } \\
\text { crescimento exponencial. 2) A partir da pesquisa, o professor vai perguntar sobre o } \\
\text { que encontraram e como eles definem função exponencial. O objetivo é que os } \\
\text { alunos encontrem uma definição própria. Com os resultados da pesquisa, os alunos } \\
\text { farão um mapa conceitual em grupo e apresentarão para a turma. Em seguida, } \\
\text { vamos propor a análise de gráficos de várias funções para identificarem as } \\
\text { características da função exponencial. }\end{array}$} \\
\hline
\end{tabular}

Fonte: Arquivo da pesquisa.

O professor Cateto refletiu sobre os impactos de sua aula para a estudante Dl e, da mesma forma que o professor Triângulo, manifestou certa surpresa em perceber as possibilidades de aprendizagem da estudante e a sua participação: "essa parte da estudante DI e a interação do grupo com ela. Ela entendeu, então eu achei interessante que ela conseguiu também identificar a partir dos cartazes dos gráficos o que seria uma função exponencial ou não". 
Figura 5 - Cenas da aula do professor Cateto

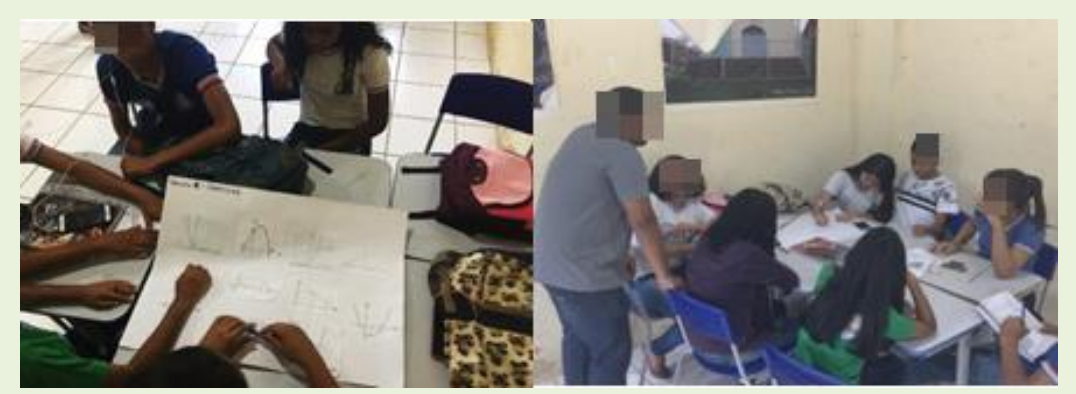

Fonte: Arquivo da pesquisa.

O professor Cateto tem pouco tempo de serviço, é contratado em regime especial, por isso ensina uma disciplina diferente da sua formação inicial, fato comum em algumas escolas públicas. O professor foi um dos que demonstrou uma atitude de abertura para novas aprendizagens e práticas inclusivas, talvez por ser mestrando em um programa de pós-graduação de ensino. Mas reconheceu suas limitações no planejamento específico da matemática, pois a sua formação inicial é a Licenciatura em física:

Em Matemática eu era mais tradicional mesmo. Chegava, colocava os conteúdos no quadro, explicava e tal, pedia assim deles ó... "O que vocês entendem disso?"; "Vocês já ouviram falar tal..." Eu era bem tradicional em Matemática diferente de Física, pois em Física eu tenho vários experimentos e eu consigo trabalhar algo de forma mais diferenciada [...] (Prof. Cateto, 2018).

Essa reflexão evidenciou que o conhecimento disciplinar da matemática não é suficiente para o professor engajar seus estudantes. Cada disciplina tem suas especificidades didáticas que são abordadas na formação inicial e aperfeiçoadas na experiência docente.

Para engajar, motivar ou envolver os estudantes em uma atividade não existe uma forma padrão que agrade a todos. É preciso testar, experimentar e "implementar múltiplas opções para envolver e motivar os alunos na aprendizagem (NUNES; MADUREIRA, p.10).

As expectativas dos professores em relação ao estudante com deficiência, ou qualquer outro estudante, pode influenciar seu desempenho. Por experiência própria, verifica-se que os estudantes sentem-se desmotivados, quando é esperado pouco deles. Esse ponto reflete na 
seleção e organização das atividades para o plano de aula. Quando o professor se envolve na organização de uma aula, esperando que seus estudantes evoluam de onde se encontram, muitas outras surpresas podem acontecer. Uma postura profissional motivadora também pode acionar o engajamento de uma turma de estudantes.

Segundo Cast (2011, p. 4), em todos os ambientes educacionais, a norma é a "variabilidade individual". Estudantes considerados "nas margens" (altas habilidades, talentosos ou com deficiência) podem ser prejudicados por não ter suas necessidades de aprendizado atendidas em um currículo de baixas expectativas.

É por meio da reflexão que os docentes terão melhores condições de pensar e sistematizar a sua ação para superar desafios peculiares ao seu ofício, confrontando-o com o ato de aprender de seus estudantes. Para que o conhecimento sobre o contexto da escola se consolide, "é importante que o professor investigue e reflita sobre a sua própria prática" (MARTINHO, 2016, p. 9).

Enfim, a reflexão final dos professores sobre a experiência vivenciada com a abordagem curricular do DUA mostrou que houve a valorização da importância de:

Trabalhar com multimídia, vídeos, tudo bem, mas a gente não tinha aqueles três princípios: engajamento, representações e ação expressão. A gente pode a partir das três referências ver como o aluno se comporta, sai da teoria e vem pra prática, a partir desse processo de formação até a teoria esses três tópicos são essenciais (Prof. Cateto, 2018).

Entretanto, eles refletiram e enfatizaram os entraves dados pelas suas condições de trabalho docente, aspectos já tensionados por Muniz, Peixoto e Madruga (2018):

O nosso tempo é muito complicado pra gente organizar todas as aulas assim, mas toda semana na perspectiva do DUA não dá, seria interessante se a gente ganhasse bem com carga horária pequena, aí daria pra trabalhar, mas realmente nossa carga horária [...], então é preciso fazer algo bem planejado (Prof. Cateto, 2018).

Ainda trouxeram para o debate a possibilidade da formação de cidadão crítico, incluindo o PAEE: "Contribuir para a formação de cidadão 
crítico atuante que venha fazer uma transformação na sociedade das pessoas com deficiência. Elas têm que estar inseridas nessa situação" (Prof. Triângulo, 2018).

Nesse momento, a reflexão provocou o "reconhecimento pelos professores de que seus atos são fundamentalmente políticos e que, portanto, podem se direcionar a objetivos democráticos emancipatórios" (ZEICHNER, 1992 apud PIMENTA, 2005, p. 26).

\section{CONSIDERAÇÕES FINAIS}

A escola é uma instituição social e, como tal, precisa refletir sobre o seu fazer pedagógico e seus reflexos na sociedade. Para tanto, espaços devem ser criados internamente para que essa reflexão possa ocorrer. É assim que uma proposta de formação de cunho investigativo pode promover esse exercício reflexivo, favorecendo um retorno à própria prática, de modo a provocar o profissional para uma mudança na sua ação pedagógica.

A prática habitual dos docentes foi confrontada pelos referenciais teóricos metodológicos compartilhados na formação, fazendo-os avaliar, se essa atendia ou não à universalidade dos educandos em sala de aula, incluindo o estudante com DI. Constatamos que os professores conseguiram: 1. Perspectivar mudanças curriculares e propor outras formas (DUA) de organizar a sua aula e/ou ministrar os conteúdos de matemática, de modo que todos os estudantes pudessem interagir, participar e atuar de forma ativa;

2. Experienciar um processo de reflexão sobre sua própria prática, tensionando-a, problematizando suas ações, analisando a natureza inclusiva ou não de seu fazer docente;

3. Avançar nas compreensões sobre os temas deficiência, inclusão, ensino de matemática, conteúdos, e, sobretudo, a respeito de quem é seu aluno olhando-o antes de tudo como "pessoa", pois foi verificado um completo desconhecimento sobre esses temas. 
4. Refletir sobre suas condições de trabalho docente que impedem uma prática favorável a todos os estudantes: salas de aula numerosas, falta de articulação com o AEE e formação continuada para o atendimento na sala comum, etc.

5. Criticar a viabilidade da proposta do DUA no contexto das escolas em que estão inseridos (tempo escolar versus conteúdos a ministrar) e da precariedade da profissão docente (carga horária elevada para dar conta).

Face ao exposto, podemos dizer que os professores quando provocados com referenciais teóricos manifestam disposição para realizar uma prática mais inclusiva. No entanto, encontram impedimentos que vão além da sua alçada, pois envolvem subsídios políticos/pedagógicos que promovam formação continuada, trabalho colaborativo com a equipe escolar, reestruturação de tempo, espaços, número de estudantes na turma, etc.

Na perspectiva esboçada até aqui, podemos afirmar que a formação inicial ou continuada articula saberes e fazeres pedagógicos, que além de contribuírem para construção de redes e compartilhamento de experiências não deixa de ser também um espaço de autoformação, uma vez que há uma (re)elaboração do conhecimento no tecer do trabalho coletivo; apesar de muitas vezes ser uma tarefa individualizada e solitária.

O professor precisa ter consciência de que as transformações sociais têm requerido uma educação plena de significados, tendo por finalidade levar o sujeito e, ele próprio, a aprender em um processo de ação-reflexãoação. Para que isso ocorra, os espaços formativos precisam criar conversações reflexivas que abordem ações curriculares na diversidade e que ultrapassem discussões sobre adaptações curriculares e técnicas, necessárias, mas insuficientes para o debate sobre o currículo escolar na promoção de uma inclusão real e uma educação pública de qualidade.

\section{REFERÊNCIAS}

AFONSO, A. Comunidades de Aprendizagem: Um Modelo para gestão da Aprendizagem. In: CONFERÊNCIA INTERNACIONAL DE TECNOLOGIAS DE 
INFORMAÇÃO E COMUNICAÇÃO NA EDUCAÇÃO, 2., 2001, Braga. Anais eletrônicos... Braga: Portugal, 2001, p. 427-432.

ALMEIDA; SILVA, M. G. M. da. Currículo, Tecnologia e Cultura Digital: espaços e tempos de Web Currículo. Revista e-curriculum, v. 7, n.1, 2011.

BRASIL. Constituição da República Federativa do Brasil. Brasília, DF: Senado Federal: Centro Gráfico, 1988.

BRASIL. Lei de Diretrizes e Bases da Educação Nacional. Lei 9394, 20 de dezembro de 1996. Presidência da República, Casa Civil, Subchefia para Assuntos Jurídicos. Brasília, DF: 1996.

BRASIL. Parâmetros Curriculares Nacionais - Adaptações Curriculares: Estratégias para a educação de alunos com necessidades educativas especiais. Brasília, DF: Ministério da Educação e do Desporto/Secretaria de Educação fundamental, 1999.

BRASIL. Decreto 7611, de 17 de novembro de 2011. Revoga o Decreto $\mathrm{n}$. 6.571, de 17 de setembro de 2008. Dispõe sobre a educação especial, o atendimento educacional especializado e dá outras providências.

Presidência da República, Casa Civil, Subchefia para Assuntos Jurídicos, Brasília, DF: 2011.

BRASIL. Lei Brasileira da Inclusão n. 13.146, de 06 de Julho de 2015.

Presidência da República, Casa Civil, Subchefia para Assuntos Jurídicos. Brasília, DF, 2015.

CAST. Universal Design for Learning Guidelines, version 2.0. Wakefield, MA: 2011. Disponível em: http://www.udlcenter.org/aboutudl/udlguidelines /downloads. Acesso em 14 jun. 2019.

CAST. UDL \& the Learning Brain. Wakefield, MA: 2018.

Disponível em: de http://www.cast.org/our-work/publications/2018/udllearning-brain-neuroscience.html. Acesso em: 12 mai. 2019.

DINIZ-PEREIRA, J. E. Da racionalidade técnica à racionalidade crítica: formação docente e transformação social. Perspectivas em Diálogo. Revista de Educação e Sociedade, v. 01, n. 01, 2014. Disponível em: http://www.seer.ufms.br/index.php/persdia. Acesso em: 12 nov. 2018.

KRANZ; C. R. Os jogos com regras na educação matemática inclusiva. Natal, RN, 2011 . 290 f. Tese (Doutorado em Educação) - Universidade Federal do Rio Grande do Norte, 2011.

MACEDO, R. S. A etnopesquisa crítica e multirreferencial nas ciências humanas e na educação. Salvador: EDUFBA, 2004. 
MACEDO, R. S. Atos de Currículo formação em ato?: para compreender, entretecer e problematizar currículo e formação. Ilhéus: Editus, 2011.

MAGINA, S. (RE)Significar as Estruturas Multiplicativas a partir da formação 'Ação-Reflexão-Planejamento-Ação' do professor. Edital Universal, Projeto $\mathrm{n}^{\circ}$ 471247/2008-1. CNPq. 2008.

MANRIQUE, A. L.; MARANHÃO, M. C. S. de A. Políticas Públicas e o Projeto "Desafios para a Educação Matemática Inclusiva". In: MANRIQUE, A. L.; MARANHÃO, M. C. S. de A.; MOREIRA, G. E (Org.). Desafios da Educação Matemática Inclusiva: Formação de professores. São Paulo: Editora Livraria da Física, 2016. p. 23-38.

MARTINHO, M. H. Desafios da Educação Matemática Inclusiva: Formação de professores. (Prefácio) p. 7-12. São Paulo: Editora Livraria da Física, 2016.

MERLINI, V. L.; SANTOS, A. dos; MAGINA, S. M. P. Estratégias formativas: um elemento potencializador para ressignificação da prática docente.

Educação Matemática e Pesquisa, São Paulo, v.19, n.1, 121-140, 2017.

MEYER, A.; ROSE, D. H., GORDON, D. Universal Design for Learning: Theory and Practice. Wakefield, MA: CAST, 2000. Disponível em:

http://udltheorypractice.cast.org/home? 12. Acesso: 15 mai 2019.

MOREIRA, L. C.; BAUMEL, R. C. R. C; Currículo em Educação Especial: Tendências e Debates. Educar em Revista, n.17, 2001. Disponível em: http://www.educaremrevista.ufpr.br/arquivos_17/moreira_baumel.pdf. Acesso em: 15 mai. 2015.

MOREIRA, P. C.; DAVID, M. M. M. S. O conhecimento matemático do professor. Revista Brasileira de Educação. 2005. Disponível em:

http://www.scielo.br/pdf/rbedu/n28/a05n28.pdf. Acesso em: 12 abr. 2018.

MUNIZ, S. C.; PEIXOTO, J. L. B; MADRUGA, Z. E. F. Desafios da inclusão de surdos na aula de matemática. In: Revista Cocar, v.12, n. 23, 2018.

MUNIZ, S. C. S. A inclusão de surdos nas aulas de Matemática: uma análise das relações pedagógicas envolvidas na tríade Professora- Intérprete-Surdo. Ilhéus, BA, 2018. $116 \mathrm{f}$. Dissertação (Mestrado em Educação Matemática) Universidade Estadual de Santa Cruz, UESC, 2018.

NUNES, C.; MADUREIRA, I. Desenho Universal para Aprendizagem: Construindo práticas pedagógicas inclusivas, Da investigação às práticas, $v$. 5, n. 2, 2015.

PAGANELLI, R. Flexibilizações vs. adaptações curriculares: como incluir alunos com deficiência intelectual. Diversa. Instituto Rodrigo Mendes, 2017. 
Disponível em: https://diversa.org.br/artigos/flexibilizacoes-adaptacoescurriculares-como-incluir-alunos-deficiencia-intelectual/. Acesso em: 12 mai. 2019.

PIMENTA, S. G. e LIMA, M. S. L. Estágio e Docência. 2. ed. São Paulo: Cortez, 2004.

PIMENTA. S. G. Professor reflexivo: construindo uma crítica. In: PIMENTA, S. G.; GHEDIN, E. (Orgs.). Professor reflexivo no Brasil: gênese e crítica de um conceito. 3 ed. São Paulo: Cortez, 2005. p. 17-52.

SACRISTÁN, J. G. Saberes e incertezas sobre o currículo. Tradução: Alexandre Salvaterra. Porto Alegre: Penso, 2013.

SILVA, L. G. dos S. Educação Inclusiva: práticas pedagógicas para uma escola sem exclusões. São Paul: Paulinas, 2014.

SANTOS, M. P. dos. Desenho Universal para a Aprendizagem. Dislexia - Novos temas Novas perspectivas. Disponível em:

https://www.academia.edu/24634089/Desenho_Universal_para_a_Aprendiza gem. Acesso em: 13 abr. 2019.

SCHÖN, D. A. Educando o Profissional Reflexivo: um novo design para o ensino e a aprendizagem. Trad. Roberto Cataldo Costa, Porto Alegre: Artmed, 2000.

SCHÖN, D. A. Formar professores como profissionais reflexivos. In: NÓVOA, A. (Org.). Os professores e sua formação. Lisboa: Dom Quixote, 1992. p. 77-91.

ZERBATO; MENDES, G. E. Desenho universal para a aprendizagem como estratégia de inclusão escolar. Educação Unisinos, v. 22, n. 2. 147-155, 2018.

Recebido em: 17 de julho de 2019 Aprovado em: 26 de novembro de 2019 